\title{
Comparison of Thermal Energy Lost through Exhaust Gases at Various Engine Speeds and Torque Loads for Diesel and Biodiesel Fuels
}

\author{
George Orido ${ }^{1}$, Prof. Godfrey Ngunjiri ${ }^{2,}$ Dr. Musa Njue ${ }^{3}$ \\ ${ }^{1}$ (Agricultural Engineering/ Egerton University, Kenya) \\ ${ }^{2}$ (Agricultural Engineering/ Egerton University, Kenya) \\ ${ }_{3}^{3}$ (Agricultural Engineering/ Egerton University, Kenya)
}

\begin{abstract}
This paper compares amount of thermal energy lost through exhaust gases when an engine was operated on diesel and biodiesel. The study used a $4.7 \mathrm{hp}(3.5 \mathrm{~kW})$ single cylinder, four-stroke, multi-fuel engine which was operated on diesel and biodiesel fuels. Experiments were conducted for the two fuels at engine speeds of 1000, 1250 and $1500 \mathrm{rpm}$ in accordance with the manufacturer's recommendations. The engine was tested for torque loads of 6 to $22 \mathrm{Nm}$ at intervals of $4 \mathrm{Nm}$ for speeds and fuels studied. The instrumentation of the engine was mainly equipped with data acquisition system and software for analysis. Exhaust gas mass flow rate and temperature measurements were used to determine lost thermal energy. Lost heat energy depended on the temperature of the waste heat gases and mass flow rate of exhaust gas. The energy lost in exhaust gases increased substantially with increased exhaust gas temperature. The results showed that more energy was lost through exhaust when the engine used biodiesel as compared to when it was fueled on diesel. Maximum heat loss through exhaust was $18.7 \%$ of fuel energy when the engine used biodiesel at a speed of $1500 \mathrm{rpm}$ and a torque load of $14 \mathrm{Nm}$.
\end{abstract}

Keywords: Engine Speed, Enthalpy, Exhaust Gases, Thermal Energy, Torque Load

\section{Introduction}

Exhaust gases immediately leaving the engine can have high temperatures. Consequently, these gases have high heat content, carried away as exhaust emission. In general, diesel engines have an efficiency of about $35 \%$ and thus the rest of the input energy is wasted. Despite recent improvements of diesel engine efficiency, a considerable amount of energy is still expelled to the ambient with the exhaust gas. The mass flow rate of exhaust gas is a function of the engine size and speed, hence the larger the engine size and the higher the speed, the more the exhaust gas heat. Compared to the composition of air, the diesel exhaust gas contains increased concentrations of water vapour and carbon dioxide. These are the main combustion products. The concentrations of both water vapour and carbon dioxide can vary from a few percent, up to about $12 \%$ in diesel exhaust. These combustion products displace oxygen, the concentration of which can vary from a few percent, up to about $17 \%$ (compared to $21 \%$ in ambient air). The main component of diesel exhaust, just as is the case with ambient air, is nitrogen [1]. By comparison, the concentrations of diesel exhaust pollutants are very small and for the purpose of calculating the physical properties of diesel exhaust gas, they can be neglected. Moreover, studies on total energy distribution from an internal combustion engine has shown that out of the possible $100 \%$ fuel energy content in an engine, $35 \%$ is useful as brake power, $30 \%$ is lost in the cooling system, 5\% is lost through radiation and approximately 30\% is lost through the engine exhaust [2]. As an approximation, the properties of air can be used for diesel exhaust gas calculations. The error associated with neglecting the combustion products is usually no more than about $2 \%$. In a more rigorous approach, corrections must be taken to account for the actual exhaust gas composition (increased water vapour and carbo dioxide, decreased oxygen). An additional difficulty with this approach is the necessity to account for the variable exhaust gas composition, which changes with the engine load factor and the air-to-fuel ratio [3]. Physical properties of mixtures of gases, and methods to calculate them from the properties of components can be found in the literature [4]. In addition to the physical properties, knowledge of certain other exhaust gas parameters is important. These include exhaust gas temperature which is of special importance for the design of catalytic after treatment devices, as catalyst performance is a function of temperature and exhaust gas flow rate. Another important parameter is the maximum pressure drop through the exhaust system, caused by the hydraulic resistance of exhaust system components. This parameter, commonly referred to as the "engine backpressure" requires that the engine perform additional pumping work, and has other impacts on engine operation. In the light of the above discussion based on introduction, it is hoped that this paper on lost thermal energy will make some contribution to existing knowledge in the wide and ever changing field of engineering. In addressing the knowledge gap, the paper seeks to propose a study on efforts to design more energy efficient engines with better 
heat transfer and lower exhaust temperatures. In addition, if some of this waste heat could be recovered, a considerable amount of primary fuel could be saved.

\section{Materials and Methods}

The experimental set-up consisted of a single cylinder, four-stroke, multi-fuel engine connected to an eddy current dynamometer for loading at various engine speeds for diesel and biodiesel fuels. Experiments were conducted for the two fuels at engine speeds of 1000, 1250 and $1500 \mathrm{rpm}$ in accordance with the manufacturer's recommendations. The engine was tested for torque loads of 6 to $22 \mathrm{Nm}$ at intervals of $4 \mathrm{Nm}$ for the speeds and fuels studied. The dynamometer was bidirectional. The shaft mounted finger type rotor ran in a dry gap. A closed circuit type cooling system permitted for a sump. Dynamometer load measurement was from a strain gauge load cell and speed measurement was from a shaft mounted three hundred sixty pulses per revolution rotary encoder. To control the speed, a set speed was given to the controller. If the measured speed of the shaft was less than that of the set speed, the load was decreased. If the measured speed of the shaft was greater than that of the set speed, then the load was increased. Since the engine had sufficient torque to attain the set speed, this maintained a constant speed. To control the load, a set load was given to the controller. If the measured load on the dynamometer was greater than that of the set load, the load was decreased. If the measured load on the dynamometer was less than that of the set load, then the load was increased. Since the engine had sufficient torque to attain the set load, this maintained a constant load while the speed varied.

\subsection{Heat Lost through Exhaust}

The setup enabled the measurement and collection of the following data: fuel consumption ( $\mathrm{kg} / \mathrm{hr})$; air consumption $(\mathrm{kg} / \mathrm{hr})$; exhaust gas inlet temperature $\left({ }^{\circ} \mathrm{C}\right)$; and ambient temperature $\left({ }^{\circ} \mathrm{C}\right)$. The instrumentation of the engine was mainly equipped with a data acquisition system and ICE Software. Data was collected using LabView 9.0. LabView based software (Enginesoft) was used for engine performance analysis and evaluation. Data was displayed on a windows based personal computer screen in real time basis and the results were also recorded in Excel file format. From the data collected, recorded values of air and fuel consumption; and exhaust gas to calorimeter inlet temperature were used in calculations. The specific heat capacity of exhaust gas was used as $1.006 \mathrm{~kJ} / \mathrm{kg} \cdot \mathrm{K}$. The ambient temperature was recorded as $24^{\circ} \mathrm{C}$. The quantity of heat lost in the exhaust gas was determined as given in (1)

$\dot{Q}_{L}=\left(\dot{m}_{a}+\dot{m}_{f}\right) \times C_{p} \times\left(T_{i}-T_{a m b}\right)$

Where:

$\dot{Q}_{L}=$ energy lost in exhaust gas $(\mathrm{kJ} / \mathrm{h})$

$\dot{m}_{\alpha}=$ air consumption $(\mathrm{kg} / \mathrm{h})$

$\dot{m}_{f}=$ fuel consumption $(\mathrm{kg} / \mathrm{h})$

$C_{p}=$ specific heat of exhaust gas $(\mathrm{kJ} / \mathrm{kg} \cdot \mathrm{K})$

$T_{i}=$ exhaust gas to calorimeter inlet temperature $\left({ }^{\circ} \mathrm{C}\right.$ )

$T_{a m b}=$ ambient temperature $\left({ }^{\circ} \mathrm{C}\right)$

\subsection{Thermal Energy Lost through Exhaust at 1000 rpm}

\section{Results and Discussion}

The results for heat lost through exhaust when the engine was operated on diesel fuel at a speed of $1000 \mathrm{rpm}$ show that heat lost through exhaust was $0.9 \%$ higher than when the engine used biodiesel at a torque load of $6 \mathrm{Nm}$. Heat lost through exhaust corresponding to $1000 \mathrm{rpm}$ and $6 \mathrm{Nm}$ was $2 \%$ of the fuel energy for diesel fuel and $1.6 \%$ of the fuel energy for biodiesel fuel. When the torque load was increased to $10 \mathrm{Nm}$, heat lost through exhaust for diesel fuel was $8.9 \%$ lower than biodiesel fuel. Importantly, heat lost through exhaust at a torque load of $10 \mathrm{Nm}$ was $2.5 \%$ of the fuel energy for diesel fuel and $2.6 \%$ of the fuel energy for biodiesel. While maintaining the engine speed at $1000 \mathrm{rpm}$ and increasing the torque load at an interval of $4 \mathrm{Nm}$ to $14 \mathrm{Nm}$, heat lost through exhaust corresponding to this load for diesel fuel was $24 \%$ lower than biodiesel fuel. Heat lost though exhaust at $1000 \mathrm{rpm}$ and $14 \mathrm{Nm}$ was $5.2 \%$ of the fuel energy for diesel fuel and $5.6 \%$ of the fuel energy for biodiesel. Similarly, at a torque load of $18 \mathrm{Nm}$, heat lost through exhaust for diesel fuel was $14.6 \%$ lower than biodiesel fuel. Loading the engine at $18 \mathrm{Nm}$ resulted in heat lost though exhaust as $7.1 \%$ of the fuel energy for diesel and $7.7 \%$ of the fuel energy for biodiesel. However, at a torque load of $22 \mathrm{Nm}$, heat lost through exhaust result was 3\% lower when the engine was operated on diesel in comparison to biodiesel. Finally, heat lost through exhaust at a torque load of $22 \mathrm{Nm}$ was $7 \%$ of the fuel energy for diesel and $7.3 \%$ of the fuel energy for biodiesel fuel. The regression analysis gave the coefficient of determination $\left(\mathrm{R}^{2}\right)$ as 0.9634 and 0.941 
corresponding to diesel and biodiesel as illustrated in Fig. 1. Table 1 shows heat lost through exhaust at a speed of $1000 \mathrm{rpm}$ for diesel and biodiesel fuels.

Table 1: Heat lost through exhaust at $1000 \mathrm{rpm}$

\begin{tabular}{|l|l|l|l|l|l|}
\hline Fuel & \multicolumn{5}{|c|}{ Heat Lost through Exhaust $(\mathrm{kJ} / \mathrm{h})$} \\
\hline Diesel & 989.8614 & 1409.5496 & 2390.5778 & 3668.3981 & 3957.1291 \\
\hline Biodiesel & 981.0659 & 1535.2942 & 2965.4695 & 4204.5903 & 4076.2986 \\
\hline
\end{tabular}

\subsection{Thermal Energy Lost through Exhaust at 1250 rpm}

Increasing the engine speed to $1250 \mathrm{rpm}$ gave the results of heat lost through exhaust as $8.7 \%$ lower when diesel fuel was used as compared to biodiesel at a torque load of $6 \mathrm{Nm}$. Heat lost through exhaust corresponding to $1250 \mathrm{rpm}$ and $6 \mathrm{Nm}$ was $2.3 \%$ of the fuel energy for diesel fuel and $2.6 \%$ of the fuel energy for biodiesel fuel. Moreover, heat lost through exhaust for diesel fuel was $13.1 \%$ lower than biodiesel at a torque load of $10 \mathrm{Nm}$. Importantly, heat lost through exhaust at a torque load of $10 \mathrm{Nm}$ was $2.7 \%$ of the fuel energy for diesel fuel and $3.2 \%$ of the fuel energy for biodiesel. Similarly, at the engine speed of $1250 \mathrm{rpm}$ and a torque load of $14 \mathrm{Nm}$, heat lost through exhaust for diesel fuel was 42.2\% lower than biodiesel. Heat lost though exhaust at $1250 \mathrm{rpm}$ and $14 \mathrm{Nm}$ was $3.3 \%$ of the fuel energy for diesel fuel and $4.9 \%$ of the fuel energy for biodiesel. However, when the torque load was increased to $18 \mathrm{Nm}$, heat lost through exhaust was $33.7 \%$ lower and at $22 \mathrm{Nm}$, heat lost through exhaust was 19\% lower when the engine used diesel in comparison to biodiesel. Loading the engine at $18 \mathrm{Nm}$ resulted in heat lost though exhaust as 5.5\% of the fuel energy for diesel and $6.9 \%$ of the fuel energy for biodiesel. Finally, heat lost through exhaust at a torque load of $22 \mathrm{Nm}$ was $6.2 \%$ of the fuel energy for diesel and $7.7 \%$ of the fuel energy for biodiesel fuel.

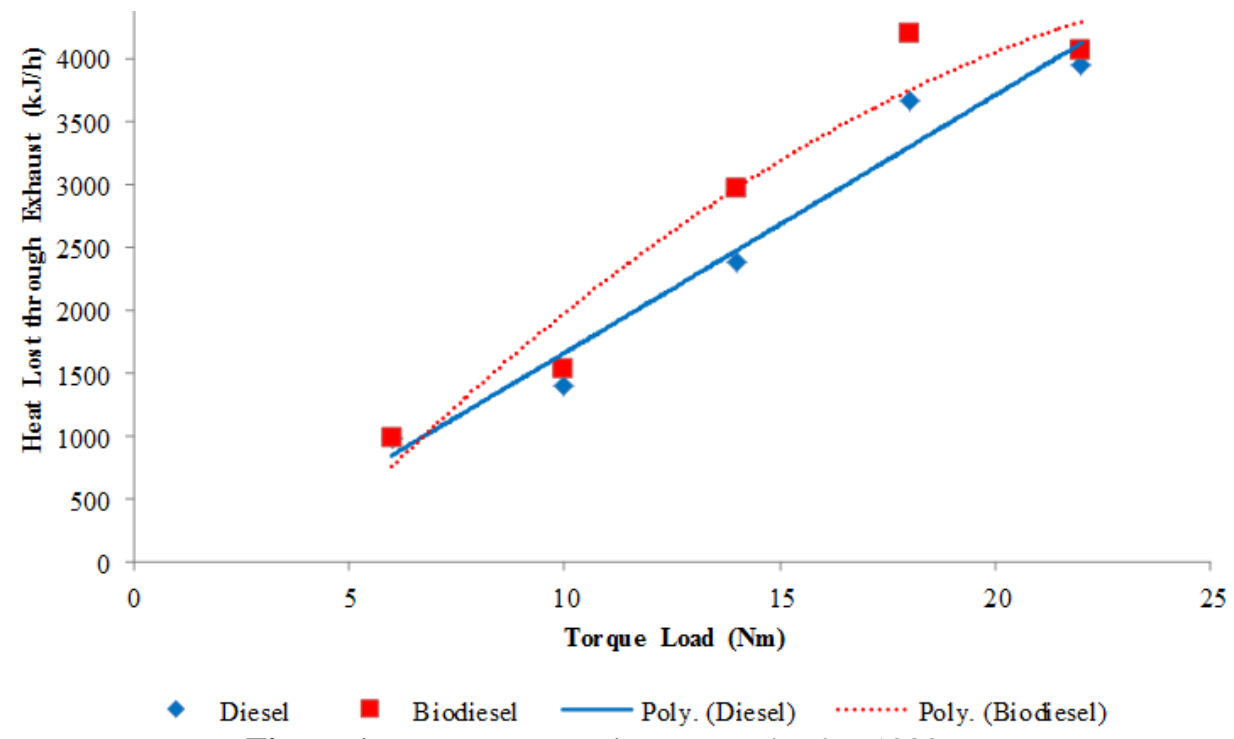

Figure 1: Lost energy against torque load at $1000 \mathrm{rpm}$

The results as analyzed at 5\% level of significance show that both the engine load and speed had a significant effect on the lost energy when the engine was operated on diesel. The calculated F-value for the load of 47.1302 was greater than the corresponding critical F-value of 3.84. Similarly, the calculated F-value for the speed of 52.4387 was greater than the corresponding critical value of 4.46 . The regression analysis gave the coefficient of determination $\left(\mathrm{R}^{2}\right)$ as 0.993 and 0.9678 corresponding to diesel and biodiesel as illustrated in Fig. 2. Table 2 shows the results of heat lost through exhaust at a speed of $1250 \mathrm{rpm}$ for the two fuels. Studies have shown that the energy lost in exhaust gases increases substantially with increased exhaust gas temperature $[5,6]$.

Table 2: Calculated heat lost through exhaust at $1250 \mathrm{rpm}$

\begin{tabular}{|l|l|l|l|l|l|}
\hline Fuel & \multicolumn{5}{|c|}{ Heat Lost through Exhaust (kJ/h) } \\
\hline Diesel & 1931.0414 & 2061.5348 & 2617.9890 & 3782.0884 & 4819.2337 \\
\hline Biodiesel & 2098.7024 & 2330.8797 & 3721.5741 & 5056.1765 & 5734.7508 \\
\hline
\end{tabular}




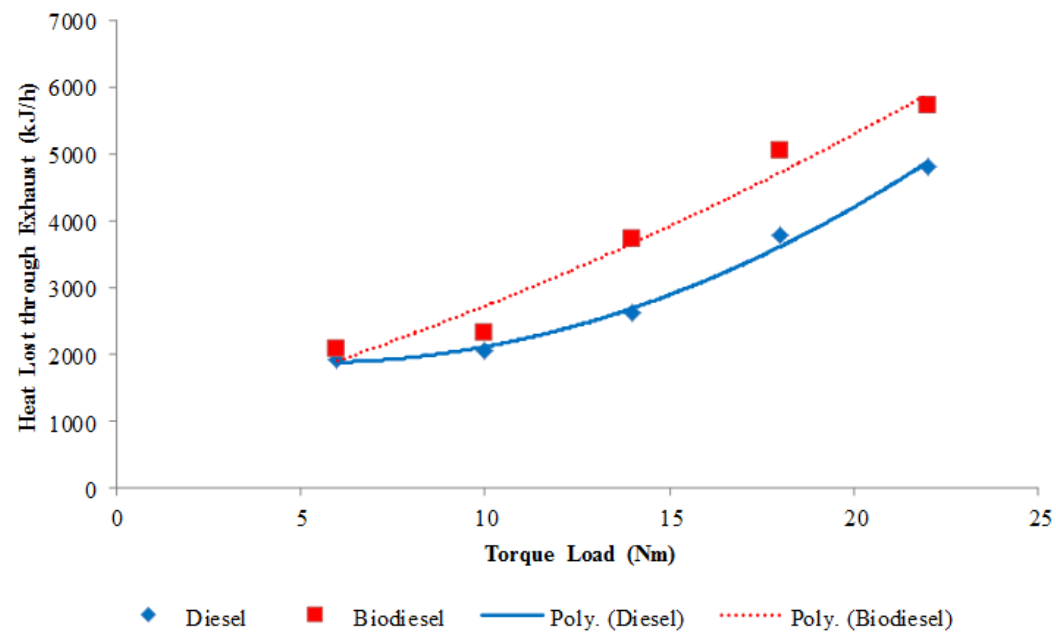

Figure 2: Lost energy against torque load at $1250 \mathrm{rpm}$

\subsection{Thermal Energy Lost through Exhaust at 1500 rpm}

Comparatively, when the engine was operated at a speed of $1500 \mathrm{rpm}$ with a torque load of $6 \mathrm{Nm}$, heat lost through exhaust for diesel fuel was $20.1 \%$ lower than biodiesel. Heat lost through exhaust corresponding to $1500 \mathrm{rpm}$ and $6 \mathrm{Nm}$ was $4.4 \%$ of the fuel energy for diesel fuel and $18.2 \%$ of the fuel energy for biodiesel fuel. Subsequently, at a torque load of $10 \mathrm{Nm}$, heat lost through exhaust for diesel fuel was $22.8 \%$ lower than biodiesel. Importantly, heat lost through exhaust at a torque load of $10 \mathrm{Nm}$ was $5.3 \%$ of the fuel energy for diesel fuel and $16.6 \%$ of the fuel energy for biodiesel. Similarly, at a torque load of $14 \mathrm{Nm}$, heat lost through exhaust was $21.7 \%$ lower when the engine used diesel as compared to biodiesel. Heat lost though exhaust at $1500 \mathrm{rpm}$ and $14 \mathrm{Nm}$ was $6.7 \%$ of the fuel energy for diesel fuel and $18.7 \%$ of the fuel energy for biodiesel. Loading the engine at $18 \mathrm{Nm}$ showed that heat lost through exhaust for diesel fuel was $21.5 \%$ lower than biodiesel. Heat lost through exhaust in relation to $1500 \mathrm{rpm}$ and $18 \mathrm{Nm}$ was $7.2 \%$ of the fuel energy for diesel fuel and $16.8 \%$ of the fuel energy for biodiesel fuel. Finally, at a torque load of $22 \mathrm{Nm}$, heat lost through exhaust was $22.9 \%$ lower when the engine used diesel in comparison to biodiesel. Relatively, heat lost through exhaust at a torque load of $22 \mathrm{Nm}$ was $7.4 \%$ of the fuel energy for diesel fuel and $12.6 \%$ of the fuel energy for biodiesel. The results as analyzed at 5\% level of significance show that both the engine load and speed had a significant effect on the lost energy when the engine was operated on biodiesel. The calculated F-value for the load of 45.8267 was greater than the corresponding critical F-value of 3.84. Similarly, the calculated F-value for the speed of 62.6307 was greater than the corresponding critical value of 4.46. The regression analysis gave the coefficient of determination $\left(\mathrm{R}^{2}\right)$ as 0.9409 and 0.9533 corresponding to diesel and biodiesel as illustrated in Fig. 3. Table 3 presents the calculated results of heat lost through exhaust at an engine speed of $1500 \mathrm{rpm}$.

Table 3: Lost heat through exhaust at $1500 \mathrm{rpm}$

\begin{tabular}{|l|l|l|l|l|l|}
\hline Fuel & \multicolumn{5}{|c|}{ Heat Lost through Exhaust (kJ/h) } \\
\hline Diesel & 2859.3147 & 3384.1830 & 4654.8988 & 4899.9731 & 4794.8023 \\
\hline Biodiesel & 3434.2268 & 4154.6987 & 5663.3434 & 5955.2175 & 5891.7099 \\
\hline
\end{tabular}

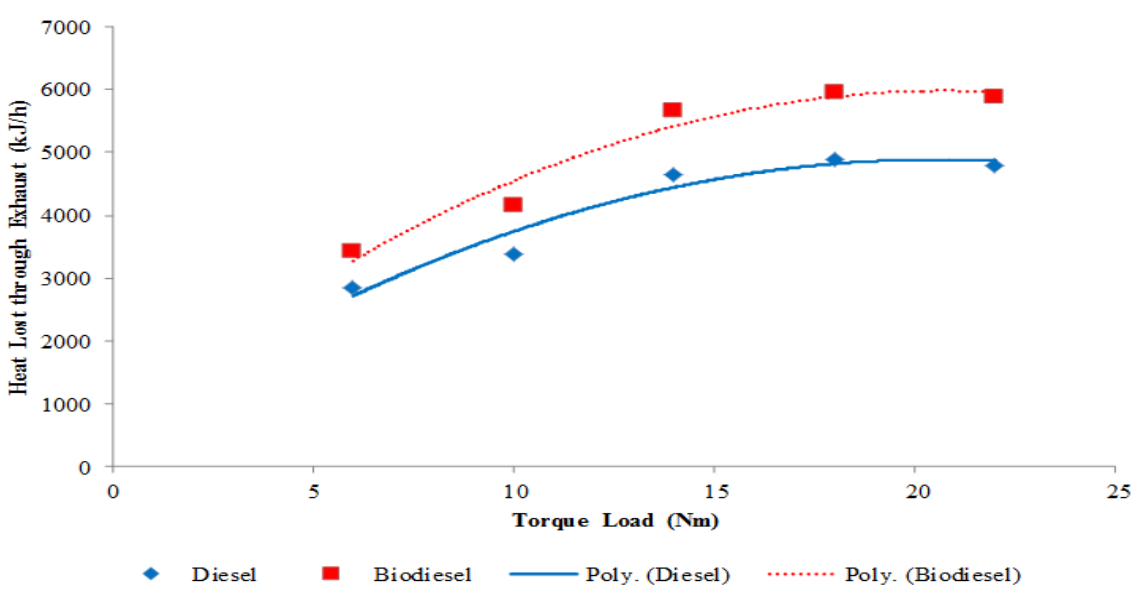

Figure 3: Lost energy against torque load at $1500 \mathrm{rpm}$ 


\section{Conclusion}

Based on this research, the peak thermal energy lost through the exhaust was $7.4 \%$ of the fuel energy when the engine was operated on diesel. When the engine used biodiesel the peak thermal energy lost through the exhaust was $18.7 \%$ of the fuel energy. The peak heat loss through the exhaust was $18.1 \%$ lower when the engine was fueled on diesel than when biodiesel was used. The lost energy increased with increased exhaust gas temperature at higher engine speeds and loads.

\section{References}

[1] T. W. Kirchstetter, R. A. Harley, N. M. Kreisberg, M. R. Stolzenburg, and S. V. Hering, On-road measurement of fine particle and nitrogen oxide emissions from light- and heavy-duty motor vehicles, Atmosphere and Environment, 33 (2), 1999, 955-968.

[2] J. S. Jadhao and P. G. Thombare, Review on exhaust gas heat recovery for internal combustion engine, International Journal of Engineering and Innovative Technology, 2(12), 2013, 93-100.

[3] J. Yanowitz, R. L. McCormick, and M. S. Graboski, In-use Emissions from Heavy-duty Diesel Vehicles, Environmental Science Technology, 34, 2000, 729-740.

[4] R. C. Reid, J. M. Prausnitz, and B. E. Poling, The properties of gases and liquids (4th edition, New York, McGraw-Hill, 1987).

[5] M. Alam, J. Song, R. Acharya, A. Boehman and K. Miller, Combustion and emissions performance of low sulfur, ultra-low sulfur and biodiesel blends in a DI diesel engine, Society of Agricultural Engineers, 4, 2004, 3024-3035.

[6] M. Canakci, Performance and emissions characteristics of biodiesel from soybean oil, Proc I MECH E Part D J, Automobile Engineering, D7, 915-922. 